\title{
Progress Towards Unique Patient Identification and Case-Based Surveillance within the Southern African Development Community (SADC)
}

Kerensa Govender ( $\square$ kgovender@heroza.org )

Wits Health Consortium Pty Ltd https://orcid.org/0000-0003-2412-2355

Lawrence Long

Boston University School of Public Health

Jacqui Miot

Wits Health Consortium Pty Ltd

Research article

Keywords: Unique patient identifier, case-based surveillance, patient tracking, linkage, health-systems strengthening

Posted Date: December 1st, 2020

DOl: https://doi.org/10.21203/rs.3.rs-115169/v1

License: (c) (i) This work is licensed under a Creative Commons Attribution 4.0 International License. Read Full License 


\section{Abstract}

Background: Despite significant advances within the South African Development Community (SADC) in making HIV care more accessible through universal prevention, testing, and treatment policies, the mobile nature of the population presents a challenge to tracking and linking of patients to HIV care, and other health services. Case-based surveillance (CBS) through individual-level clinical data linked and tracked with a unique patient identifier (UPI) has been recommended to create a more person-centred health information system, and is an important policy consideration within PEPFAR-supported countries.

Methods: We conducted a landscape analysis of UPI and CBS implementation within selected SADC countries through a mixed-methods study design that included the following activities: 1) a literature review to gather evidence around UPI implementation and patient-tracking in the SADC region; 2) an assessment of progress towards UPI and CBS implementation within relatively high HIV prevalence SADC countries; and 3) a case-study of UPI implementation within selected South African primary healthcare (PHC) facilities.

Results: Research into UPI implementation and movement towards CBS for the SADC region is lacking. Existing patient identification methods, such as name and surname, may not uniquely identify a patient or guarantee confidentiality. If a UPI has been assigned these are often facility specific, i.e. a patient can be tracked within a facility, but not across facilities. Other challenges include multiple identifiers allocated to one patient, incorrectly captured UPIs, preference for paper-based records and a lack of integration between numerous stand-alone health-information systems, e.g. laboratory databases and electronic health records, resulting in fragmented health information which limits patient-tracking and monitoring. Our analysis revealed that most countries were in the early-middle stages of the shift towards CBS and had challenges with UPI implementation. Our South African case-study found that the required identifier, which is critical for record-linkage and systems-integration, may often not be recorded.

Conclusions: Until a fully functional and reliable UPI is in place difficulties tracking patients across prevention and care cascades will continue. Progress towards CBS was lagging in all countries, consistently hampered by a preference for paper-based records and difficulties implementing the UPI, underscoring a need for increased policy efforts and support to address this gap.

\section{Background}

The World Health Organization (WHO) defines the health system of any country or region as the collection of all organizations, people and actions whose primary intent is to promote, restore, or maintain health (1). In the wake of any health threat, the strength of a health system at the national and international level is often challenged (2), a most pertinent example being the current COVID-19 pandemic. The need to strengthen fragile health systems, especially in low-income and resourceconstrained countries is driven by the recognition that weak health systems impede attainment of global and national targets, and are insufficiently resilient to prepare for and respond to crises (3). The HIV 
response in the Southern African Development Community (SADC) is one example of a public health initiative to strengthen the health system and facilitate greater access to care for people living with HIV (PLHIV) (4). Countries, such as South Africa, that shoulder the highest burden of HIV infection in the world, have made significant progress in making HIV care more accessible through the implementation of universal prevention, testing, and treatment policies to help curb the epidemic (5). Despite this progress, substantial challenges in linking patients to HIV care still persist, mostly due to losses of HIV diagnosed clients at pre-ART (antiretroviral) stages in Sub-Saharan Africa (6). A systematic review within the region found that a median of $68 \%$ (range 14-84\%) of patients eligible for ART actually went on to initiate treatment within the observed study period at the clinic of diagnosis(7). As a result, many countries in the region have yet to achieve key milestones, such as the 95-95-95 targets set by UNAIDS (4)(6). The implementation of a unique patient identifier (UPI) has been recommended to drive progress towards these goals through the creation of a strategic health information system to uniquely identify and track PLHIV; the UPI also provides a means to strengthen other service areas of the health system through linkage, therefore creating a more person-centred and integrated approach to healthcare(8).

A health information system which supports data collection across multiple sources at the patient level is important for improving consistency of care, treatment adherence and ultimately health outcomes, especially for more vulnerable populations such as PLHIV(9). There is however an overall paucity of reliable health system surveillance data on the African continent (10). The mobile nature of the population also makes HIV testing and long-term care more challenging (11). A limitation of commonly used facility-level surveillance programs is that the information captured does not uniquely identify the patient across the health system, often resulting in inaccurate interpretation of surveillance data (12). A UPI is specified to aid the creation of individually linked de-identified longitudinal medical records for more precise monitoring, evaluation and subsequent service improvements on a continuous basis(13). In 2017 the WHO released a set of consolidated guidelines around HIV patient monitoring, advocating for a more person-centred approach to health information data collection and reporting through case-based surveillance (CBS) by means of a UPI (14).

While most resource limited countries initially focused on aggregated monitoring within their HIV service cascade, many now recognize the need to shift towards a person centred, second generation health information system (HIS) (13). Such systems support CBS through the utilisation of individual-level clinical data tracked with a UPI (15). They are also essential for the delivery of quality HIV care and treatment which requires ongoing monitoring of clinical outcomes, daily medication adherence, and longterm retention in HIV clinical services (16). Furthermore the ability to register and track patients through linked datasets grows even more critical as countries move towards National Health Insurance (NHI) implementation(17). A UPI enables unique identification of individuals accessing healthcare which is critical to monitoring of progress towards $\mathrm{NHI}$, measured through two components requiring disaggregated and accurate data, these are: i) the proportion of the population that has access to essential quality health care services and (ii) the proportion of the population for which health costs take up a large part of household expenditures(18). The implementation of CBS for public health has therefore become an important policy consideration for all PEPFAR-supported countries (19). This investigation 
seeks to provide a landscape analysis of UPI implementation within selected SADC countries, with a more detailed analysis of each countries' progress against a set of criteria and lastly a case study of how this is being implemented on the ground within selected primary health care facilities in South Africa.

\section{Methods}

This landscape analysis was designed with the purpose of gaining an understanding of progress towards CBS implementation through the use of a UPI within the SADC region. To achieve this, we made use of a mixed-methods study design and conducted three activities: 1) a literature review to understand the current peer reviewed evidence regarding patient-tracking and UPI implementation in the SADC region; 2) an assessment of progress towards national CBS implementation through patient tracking with a UPI within relatively high HIV prevalence SADC countries; and 3) a description of UPI implementation using sites in South Africa as a case study.

\section{Activity 1: Literature review}

The purpose of this literature review is to provide an overview of research studies on patient identification and tracking systems within the SADC region, as well as the underlying drivers behind the need for a UPI in the region. The literature search was conducted in PubMed by focusing on specific variables related to health systems and patient identification, as well as the countries within in the SADC region. All possible synonyms, and keyword combinations using the OR operator, were then generated from the main key words and included in the search using Medical Subject Headings (MeSH) in PubMed. Detailed search terms are provided in Table 1.

Table 1

Key search terms for PubMed database

\begin{tabular}{|c|c|}
\hline Category & Search term combined with AND \\
\hline $\begin{array}{l}\text { Health } \\
\text { systems and } \\
\text { patient } \\
\text { identification }\end{array}$ & $\begin{array}{l}\text { "Patient Identification Systems"[Mesh] OR Identification System, Patient OR } \\
\text { Identification Systems, Patient OR Patient Identification System OR System, Patient } \\
\text { Identification OR Systems, Patient Identification OR Patient Tracking OR Patient } \\
\text { Trackings OR Tracking, Patient OR Trackings, Patient }\end{array}$ \\
\hline & $\begin{array}{l}\text { Angola[MeSH Terms]) OR Botswana[MeSH Terms]) OR Comoros[MeSH Terms]) OR } \\
\text { Democratic Republic of the Congo[MeSH Terms]) OR Swaziland[MeSH Terms]) OR } \\
\text { Lesotho[MeSH Terms]) OR Madagascar[MeSH Terms]) OR Malawi[MeSH Terms]) OR } \\
\text { Mauritius[MeSH Terms]) OR Mozambique[MeSH Terms]) OR Namibia[MeSH Terms]) } \\
\text { OR Seychelles[MeSH Terms]) OR South Africa[MeSH Terms]) OR United Republic of } \\
\text { Tanzania[MeSH Terms]) OR Zambia[MeSH Terms]) OR Zimbabwe[MeSH Terms] }\end{array}$ \\
\hline
\end{tabular}

Articles were considered for review if they were published in English between 2009 to 2019, involved a study population of adults (18 years and older) and adolescents (10-19 years) and were conducted in a SADC country. For inclusion, studies were required to address the subject of patient identification and/or 
patient tracking. All three authors were involved in the initial screening phase of titles and abstracts, as well as in the full-text assessment for eligibility and inclusion. To minimise bias in the screening and selection process, all three authors independently screened the titles and abstracts of the initial 96 publications for eligibility and inclusion for review. All conflicts were discussed by the authors until a consensus could be reached. The same process was followed for the full text assessments. The screening and selection process was conducted on the Rayyan (rayyan.qcri.org) tool for systematic reviews. Refer to Fig. 1 for further details on the study selection process.

One author then read the publications selected for inclusion and completed a data extraction form created to gather the following information: authors, study setting, main study objectives, study population, study design and study findings. A descriptive narrative synthesis was chosen as the method of data synthesis for this review

\section{Activity 2: Assessment of progress towards national CBS implementation through patient tracking with a UPI within relatively high HIV prevalence SADC countries}

For this part of the analysis country selection was informed by the 2018 UNAIDS country level HIV prevalence estimates due to the critical role of CBS in the delivery of quality HIV care and treatment. Countries reporting an HIV prevalence equal to or above the SADC region average met our inclusion criteria. Our calculations estimated the average HIV prevalence for the SADC region to be $10,5 \%(2018)$. The following SADC countries met our inclusion criteria and were included in this study: Botswana, Eswatini, Lesotho, Mozambique, Namibia, South Africa, Zambia and Zimbabwe. A toolkit, informed by the WHO stages of development for the transition from name and paper-based individual records to an electronic record coded with a UPI, was developed and used to guide data collection. The toolkit is premised upon the six essential elements of the transition to CBS, i) Person identification: assigning and using unique identifiers; ii) Investing in databases and interoperability; iii) Confidentiality and security; iv) Data analysis, quality and use; v) Transition from paper to electronic systems and vi) Sustainability of programme improvements (14). The latest PEPFAR Country Operational Plans (COP) documents for each of the selected countries served as the main information source during this exercise. Findings from these documents were supplemented with relevant literature, found through a purposive internet based search using relevant key words, or through conversation with an in-country contact, if available. Data collection occurred between June 2019 and March 2020 and represents each countries status up to end March 2020.

\section{Data analysis}

The information gathered during data collection was used to understand the progress of each of the selected SADC countries in terms of the three broad stages of development towards CBS, namely i) Early: Switch from name-based records to unique identifiers associated with a single individual in a paper- 
based health record system; ii) Middle: The widespread use of unique identifiers and the deployment of an electronic data system with a mixture of online and offline elements; and iii) Advanced: Data linked by unique identifiers in a fully online electronic health information system linked across services, facilities and with community care (14). We reviewed each of the six elements of CBS implementation development to identify gaps in progress (Refer to Table 2 for more detail on the elements of CBS implementation and stages of development). 
Table 2

A description of key elements for CBS and their stages of development

\begin{tabular}{|c|c|c|}
\hline CBS Element & $\begin{array}{l}\text { Stage of } \\
\text { development }\end{array}$ & Description of stage of development \\
\hline \multirow{3}{*}{$\begin{array}{l}\text { Person } \\
\text { identification: } \\
\text { assigning and } \\
\text { using unique } \\
\text { identifiers }\end{array}$} & Early & $\begin{array}{l}\text { Name-based record and/or aggregate data based on services, } \\
\text { not people (tally sheets) }\end{array}$ \\
\hline & Middle & Unique identifiers at facility level \\
\hline & Advanced & $\begin{array}{l}\text { Programme or national unique identifiers, people-centred } \\
\text { health record systems }\end{array}$ \\
\hline \multirow{4}{*}{$\begin{array}{l}\text { Investing in } \\
\text { databases and } \\
\text { interoperability }\end{array}$} & Early & $\begin{array}{l}\text { Low-cost paper based record system/Traditional stationary } \\
\text { costs }\end{array}$ \\
\hline & Middle & $\begin{array}{l}\text { Facility-based electronic data systems/Basic computer / } \\
\text { Open-access }\end{array}$ \\
\hline & & software \\
\hline & Advanced & $\begin{array}{l}\text { Fully interoperable data system, linkage of information from } \\
\text { multiple sources. Linkage with vital statistics, migration data. } \\
\text { Useful for tracking individuals lost to follow up, etc }\end{array}$ \\
\hline \multirow[t]{3}{*}{$\begin{array}{l}\text { Confidentiality and } \\
\text { security }\end{array}$} & Early & $\begin{array}{l}\text { Name-labelled paper files retained by the individual or kept } \\
\text { under lock and key at facility }\end{array}$ \\
\hline & Middle & $\begin{array}{l}\text { Records coded with unique identifiers without personal } \\
\text { content }\end{array}$ \\
\hline & Advanced & $\begin{array}{l}\text { National system with health record data protected by law. } \\
\text { Limited and enforced data access control }\end{array}$ \\
\hline \multirow[t]{4}{*}{$\begin{array}{l}\text { Data analysis, } \\
\text { quality and use }\end{array}$} & Early & $\begin{array}{l}\text { Data officer transfers data from paper record into electronic } \\
\text { health record or register, regular data quality reviews }\end{array}$ \\
\hline & Middle & $\begin{array}{l}\text { Programme or central-level analysis of data and creation of } \\
\text { management dashboards, and other data analysis and } \\
\text { reporting tools }\end{array}$ \\
\hline & Advanced & $\begin{array}{l}\text { Local analyses of care and programmatic capacity. } \\
\text { Standardized dashboards, data }\end{array}$ \\
\hline & & $\begin{array}{l}\text { visualization and reports. Individual care facilitated by ease of } \\
\text { data access, aggregation and review. Regular use of data for } \\
\text { decision-making at individual, facility, programme and } \\
\text { national levels }\end{array}$ \\
\hline \multirow{2}{*}{$\begin{array}{l}\text { Transition from } \\
\text { paper to electronic } \\
\text { systems }\end{array}$} & Early & $\begin{array}{l}\text { Paper based record system. Records retained at facility or by } \\
\text { individual }\end{array}$ \\
\hline & Middle & Offline electronic upload of data. On- or offline data access \\
\hline
\end{tabular}




\begin{tabular}{|c|c|c|}
\hline \multirow[t]{3}{*}{ CBS Element } & $\begin{array}{l}\text { Stage of } \\
\text { development }\end{array}$ & Description of stage of development \\
\hline & Advanced & Fully online systems used across \\
\hline & & $\begin{array}{l}\text { facilities, in community care. Links services within facility and } \\
\text { across facilities }\end{array}$ \\
\hline \multirow[t]{4}{*}{$\begin{array}{l}\text { Sustainability of } \\
\text { program } \\
\text { improvements }\end{array}$} & Early & $\begin{array}{l}\text { Patient monitoring is only system in place to track individuals } \\
\text { over time. Challenging to link individual data within and } \\
\text { between facilities }\end{array}$ \\
\hline & Middle & $\begin{array}{l}\text { Limited ability to track individuals within a facility. } \\
\text { Appointment scheduling, follow up within a facility. Within } \\
\text { facility linkage of individual information from clinic to lab and } \\
\text { pharmacy }\end{array}$ \\
\hline & Advanced & $\begin{array}{l}\text { Individual records updated in real-time with clinical, lab, } \\
\text { pharmacy and }\end{array}$ \\
\hline & & $\begin{array}{l}\text { other data. Person-based records linked with death registry } \\
\text { data }\end{array}$ \\
\hline
\end{tabular}

\section{Activity 3: A description of UPI implementation using sites in South Africa as a case study}

Our study population consisted of adult patients (18 years and older) accessing care at four public sector PHC facilities within South Africa's Gauteng province. At two facilities we examined these selected conditions/diseases: hypertension (diagnosis and treatment), diabetes (diagnosis and treatment), and TB (diagnosis and treatment, excluding drug resistant TB). At all of the facilities we examined HIV (diagnosis and treatment). Data collection for this study was approved by the Human Research Ethics Committee of the University of Witwatersrand (M171082) and the Institutional Review Board of the Boston Medical Centre (H-37230). We used a sample size of 75 medical records per disease cohort at each PHC facility. This was not meant to be a powered sample but rather meant to be descriptive and this sample size was feasible given existing work being conducted at the site. We carried out a retrospective review of medical records of adult patients (18 years and older) at four conveniently selected public sector PHC facilities within South Africa's Gauteng province. Data collection took place between December 2018 and September 2019. For each study subject, we made a note of the primary disease that the patient presented for initially, as well as which identifiers (i.e. Name, Surname, National ID, Passport number etc.) had been captured onto their medical record. No patient identifying information was collected. Each study subject was assigned a study ID number and all data collection occurred under the study ID only. Data relevant to the study was entered into a REDCap database; REDCap is a secure, web-based software platform designed to support data capture for research studies (20). All data was summarised and 
analysed using Stata Statistical Software (Release 15. College Station, TX: StataCorp LLC). Descriptive statistics, through the generation of frequency tables, were used to gain a better understanding of the level of detail of patient identifiers collected per site and per disease cohort across sites. Our goal was to understand the collection of identifiers at clinics, specifically the South African (SA) national identity (ID) number and passport/foreign passport numbers as these are critical to the implementation of the UPI based Health Patient Registration System (HPRS)(21).

\section{Results}

\section{Activity 1: Literature review}

From the 96 publications identified, 4 studies met the inclusion criteria for this review. They were conducted in three SADC countries, namely Mozambique, South Africa and Zambia. Overall the review revealed a lack of literature on patient tracking and identification systems using a unique patient identifier which have been implemented within the SADC region. Articles included in the review tended to focus on two categories: 1) existing patient identification methods and 2) patient identification and tracking of long-term health outcomes. Further detail on study characteristics can be found in Table 3. Our search revealed the need for more studies which focus on national UPI implementation within the region. 
Table 3

Characteristics of studies included in the review

\begin{tabular}{|c|c|c|c|c|c|}
\hline Authors & Country & $\begin{array}{l}\text { Main study } \\
\text { objectives }\end{array}$ & Study population & Study design & Key findings \\
\hline $\begin{array}{l}\text { Lambdin } \\
\text { et al., } \\
2012\end{array}$ & Mozambique & $\begin{array}{l}\text { To assess the } \\
\text { completeness } \\
\text { and reliability } \\
\text { of Electronic } \\
\text { Patient } \\
\text { Tracking } \\
\text { Systems } \\
\text { (EPTS) used } \\
\text { in } 16 \text { HIV care } \\
\text { and } \\
\text { treatment } \\
\text { clinics in } \\
\text { Manica and } \\
\text { Sofala } \\
\text { provinces of } \\
\text { Mozambique }\end{array}$ & $\begin{array}{l}\text { Adult }(\geq 15 \text { years } \\
\text { of age), ART- } \\
\text { naïve patients } \\
\text { receiving HIV } \\
\text { treatment at the } \\
\text { selected facilities }\end{array}$ & $\begin{array}{l}\text { Quantitative, } \\
\text { cross- } \\
\text { sectional } \\
\text { analysis to } \\
\text { assess the } \\
\text { completeness } \\
\text { and reliability } \\
\text { of data }\end{array}$ & $\begin{array}{l}\text { The electronic } \\
\text { patient tracking } \\
\text { systems for } \\
\text { HIV treatment } \\
\text { programs in } \\
\text { Manica and } \\
\text { Sofala } \\
\text { provinces of } \\
\text { Mozambique } \\
\text { had high levels } \\
\text { of } \\
\text { completeness } \\
\text { and reliability } \\
\text { justifying their } \\
\text { use. }\end{array}$ \\
\hline $\begin{array}{l}\text { Harichund } \\
\text { et al., } \\
2013\end{array}$ & South Africa & $\begin{array}{l}\text { To report the } \\
\text { development } \\
\text { and } \\
\text { feasibility of } \\
\text { a digital, } \\
\text { fingerprint- } \\
\text { based } \\
\text { participant } \\
\text { identification } \\
\text { method to } \\
\text { prevent co- } \\
\text { enrolment at } \\
\text { multiple } \\
\text { clinical trial } \\
\text { sites in Kwa- } \\
\text { Zulu Natal } \\
\text { province. }\end{array}$ & $\begin{array}{l}\text { Women enrolled } \\
\text { in HIV related } \\
\text { trials at seven } \\
\text { South African } \\
\text { Medical } \\
\text { Research Council } \\
\text { (MRC) - HIV } \\
\text { Prevention } \\
\text { Research Unit } \\
\text { (HPRU) sites }\end{array}$ & $\begin{array}{l}\text { Pre/Post } \\
\text { intervention } \\
\text { observation } \\
\text { and analysis }\end{array}$ & $\begin{array}{l}\text { The biometric } \\
\text { verification } \\
\text { system is a } \\
\text { novel approach } \\
\text { to prevent } \\
\text { participant co- } \\
\text { enrolment in } \\
\text { multiple HIV } \\
\text { prevention } \\
\text { clinical trials. }\end{array}$ \\
\hline
\end{tabular}




\begin{tabular}{|c|c|c|c|c|c|}
\hline Authors & Country & $\begin{array}{l}\text { Main study } \\
\text { objectives }\end{array}$ & Study population & Study design & Key findings \\
\hline $\begin{array}{l}\text { Wall et al., } \\
2015\end{array}$ & Zambia & $\begin{array}{l}\text { To determine } \\
\text { the feasibility } \\
\text { of } \\
\text { implementing } \\
\text { an electronic- } \\
\text { fingerprint } \\
\text { linked data } \\
\text { capture } \\
\text { system in } \\
\text { Zambia. } \\
\text { Determine the } \\
\text { acceptability } \\
\text { of this } \\
\text { system } \\
\text { among a key } \\
\text { HIV risk } \\
\text { group: female } \\
\text { sex workers } \\
\text { (FSWs). }\end{array}$ & $\begin{array}{l}\text { Female sex } \\
\text { workers } \\
\text { accessing four } \\
\text { clinics in Ndola, } \\
\text { Zambia. }\end{array}$ & $\begin{array}{l}\text { Pre/Post } \\
\text { intervention } \\
\text { qualitative } \\
\text { and } \\
\text { quantitative } \\
\text { analysis }\end{array}$ & $\begin{array}{l}\text { Implementation } \\
\text { of an electronic } \\
\text { fingerprint- } \\
\text { linked patient } \\
\text { tracking and } \\
\text { data collection } \\
\text { system was } \\
\text { feasible in this } \\
\text { relatively } \\
\text { resource- } \\
\text { limited setting } \\
\text { and was } \\
\text { acceptable } \\
\text { among FSWs } \\
\text { in a clinic } \\
\text { setting. }\end{array}$ \\
\hline $\begin{array}{l}\text { Davies et } \\
\text { al., } 2017\end{array}$ & South Africa & $\begin{array}{l}\text { To evaluate } \\
\text { long-term } \\
\text { outcomes in } \\
\text { HIV-infected } \\
\text { adolescents } \\
\text { after transfer } \\
\text { by linking } \\
\text { data from } \\
\text { four } \\
\text { International } \\
\text { epidemiology } \\
\text { Databases to } \\
\text { Evaluate } \\
\text { AlDS } \\
\text { Southern } \\
\text { Africa } \\
\text { (leDEA-SA) } \\
\text { cohorts in the } \\
\text { Western Cape } \\
\text { province } \\
\text { (WCP) with } \\
\text { Department } \\
\text { of health } \\
\text { (DoH) data }\end{array}$ & $\begin{array}{l}\text { All adolescents } \\
\text { on ART if they } \\
\text { had a valid WCP } \\
\text { DoH folder } \\
\text { number and were } \\
\text { recorded as } \\
\text { transferred out } \\
\text { between } 10 \text { and } \\
\text { <20 years of age } \\
\text { from March } 2004 \\
\text { to December } \\
2014 \text {. Cohorts } \\
\text { were selected } \\
\text { from two tertiary } \\
\text { care (Tygerberg } \\
\text { Academic } \\
\text { Hospital and Red } \\
\text { Cross War } \\
\text { Memorial } \\
\text { Children's } \\
\text { hospital) and } \\
\text { two primary care } \\
\text { (Gugulethu and } \\
\text { Khayelitsha } \\
\text { Community } \\
\text { Health Centres) } \\
\text { facilities. }\end{array}$ & $\begin{array}{l}\text { Quantitative } \\
\text { longitudinal } \\
\text { analysis }\end{array}$ & $\begin{array}{l}\text { Linking cohort } \\
\text { data to the } \\
\text { health } \\
\text { information } \\
\text { system data } \\
\text { allowed } \\
\text { efficient } \\
\text { assessment of } \\
\text { post-transfer } \\
\text { outcomes. }\end{array}$ \\
\hline
\end{tabular}

\section{Existing patient identification methods}

Two studies described existing patient identification methods and challenges (22)(23). Patient identification within and between health facilities is considered to be a challenge in much of Sub-Saharan 
Africa with existing methods of identification not unique to a patient (23). Furthermore many health clinics in the region still use patient name, date of birth, government ID, or phone number to identify patients, with record numbers also being clinic specific, making it difficult to both identify and/or follow a patient across health facilities (22). The use of patient name may also give rise to confidentiality concerns (23). Such identifiers are also often inexact and may be captured differently, for example changes in spelling of a name within and between facilities resulting in duplicate records and incomplete records due to poor data linkage (23).

\section{Patient identification and tracking of long-term health outcomes}

Four articles reported on patient identification and tracking of long-term health outcomes (22-25) Historically program specific reporting indicators have typically been hand calculated on a monthly basis in resource limited settings, from a health facility's paper-based registers, and then aggregated at the district, provincial and national-level(25). Unique patient identifiers work to strengthen fragmented health services in countries by linking data held within facilities and enabling the flow of information across the general health system (23). The creation of a complete health record was considered not only to be vital for monitoring site performance and informing national planning, but also plays a key role in the effective delivery of care over time (25). A study conducted in the Western Cape province of South Africa noted that although the collection and analysis of health outcomes over a longitudinal time period is critical for effective monitoring and evaluation, such data is often incomplete due to population mobility and the tendency to transfer silently between facilities (22). The study provides an example of the benefits of such a system where patients in the Western Cape province (WCP) of South Africa are assigned the same unique health identifier (folder number) in all services, this has shown great potential for the linking and tracking of HIV+ adolescents and health outcomes due to the resultant integration of information systems (22). A Zambian study implemented a digital identification system through a biometric linked fingerprinting system to create a unique and secure patient identification mechanism which provides integrated and real-time data (23). Although there were patient concerns about the provision of fingerprints, results indicated that such a system was feasible and effective at uniquely identifying female sex workers, a typically hard to reach, stigmatized and highly mobile population, in Zambia (23). Another South African study also highlighted the advantage of biometric identification systems over traditional identification methods for clinical trial participants; it was noted that such systems can store and provide accurate and secure patient information timeously, and also verify a person's identity without the need for documents (24).

\section{Activity 2: Assessment of progress towards national CBS implementation through patient tracking with a UPI within relatively high HIV prevalence SADC countries}

8 countries met the inclusion criteria for this analysis (Botswana, Eswatini, Lesotho, Mozambique, Namibia, South Africa, Zambia and Zimbabwe). Figure 2 presents results from the assessment of 
progress towards CBS through patient tracking with a UPI for each of these countries, classified by stage of development across the six essential elements of the transition to CBS. Full details of country specific assessments have been attached with this paper (see Additional file 1). All countries, with the exception of Zimbabwe, appear to have reached the middle-stages of development for 4 out of the 6 essential elements; results do however indicate that challenges around UPI implementation hamper the integration of stand-alone systems and patient-tracking capabilities which may in turn limit the regions potential to move towards a truly second-generation health system. Findings are reported below and point to key areas requiring further attention.

Patient identification: With the exception of Zimbabwe, the 7 remaining countries were reported to all be in the process of rolling out a national health information system which made use of both name and paper-based health records (early stage criteria) while simultaneously beginning to implement unique patient identifiers at facility level (middle stage criteria) (26)(27)(28)(29)(30)(31)(32). Eswatini makes use of the national ID number as the UPI while South Africa aims to implement a 10-digit system generated UPI known as the Health Patient Registration Number (HPRN) which is linked to a patient's SA ID number or SA/foreign passport number; other countries appear to use a system generated number, or smartcard number as a UPI. UPI implementation within these countries appears to currently focus mainly on PLHIV. PEPFAR Namibia is however working on introducing a UPI across disease areas and South Africa is in the process of rolling out the HPRS for the creation of UPI linked longitudinal health records across disease areas(21). It is also important to note that there are still challenges with implementation and use of the UPI. Mozambique, for example, is reported to have a national Electronic Patient Tracking System (EPTS) which is reliant on a UPI at most PEPFAR supported facilities but is dealing with issues of multiple UPIs being assigned to a patient within a facility(29). Zimbabwe was still in the process of developing a unique identifier at the time of conducting this assessment and therefore rated as early stage for this element(33).

Investing in databases and interoperability: All countries, besides Zimbabwe, had met the middle-stage criteria for this element due to progress in rolling out an Electronic Health Information System (eHIS) to most PEPFAR supported and national facilities. Paper-based health systems do however still exist alongside the eHIS within these countries. Integration between the two systems is manual and requires a data-capturer to transfer data into the electronic system; staff shortages and lack of training may result in incomplete and inaccurate electronic health records $(16,26,30,33-37)$. Connectivity issues are another driver of poor integration between the paper and electronic systems as seen in the more rural areas of Zambia, where information is captured on SmartCare forms which are then transported to an area with internet connectivity to be captured into Smartcare, the HIV programme system(37). Interoperability between various standalone electronic health systems is another challenge. For example, the Patient Information Management System (PIMS) in Botswana has not been integrated with the laboratory system (Integrated procurement management system(IPMS)) and requires a manual transfer of results into PIMS(26); similarly in South Africa the HIV health system TIER.Net also requires a manual transfer from other key databases, such as the national laboratory system(31). Furthermore, South Africa's eHIS or HPRS which is reliant on a system generated UPI or HPRN (linked to a patient's SA ID number or 
SA/foreign passport number) has not reached scale as yet and not been fully integrated with the facility specific Tier.net system(21)(31). Eswatini, Lesotho, Mozambique, Namibia and Zambia face interoperability challenges between their standalone eHIS, and other key databases such as the laboratory and dispensing systems in the same way $(27-29,32,38)$. Zimbabwe was considered to be at the early stage of development due to a limited number of facilities with access to the country's Electronic Patient Management System (EPMS) with most facilities reliant solely on a paper based health information system(33).

Confidentiality and security: The literature suggest that all countries are at the early stages of execution for this element as personal information is reported to still be captured into the eHIS, despite the existence of a UPI, for those currently implementing such a system (26-32,39). In Zambia, although records are coded with the unique identifier from the Smartcare card, personal data is still collected in case the card is lost to enable access to the patient record(40). Similarly, in Swaziland records on the Client Management Information System (CMIS) are coded with a UPI as well as personal content such as name and surname(34). Paper based records are most likely stored at facility level with restricted access for all countries.

Data analysis quality and use: Data analysis and data use capabilities was another area for improvement, with all countries appearing to be at the early stages. This seems to be attributed to a lack of integration between their eHIS and other health systems, as well as challenges with duplicate identifiers, clinic specific identifiers and incorrect capturing of the UPI into the eHIS, as experienced with the unique ART number in Namibia; all of which has made patient tracking and the creation of longitudinal records for more accurate reporting and monitoring difficult [25-39]. All countries remain reliant on data officers, or the implementing partners, to transfer data from paper records into the eHIS if present, and between various health systems[25-39].

Transition from paper to electronic systems: Due to the limited number of facilities with access to the ePMS system in Zimbabwe the country was considered to still be in the early stages of the transition to an eHIS $(33,39)$. The remaining countries were classified as having reached the middle stages of development as reports suggest that an eHIS has been implemented alongside paper-based records in the majority of PEPFAR supported facilities; offline upload of information into the electronic system still required $(26-32,41)$.

Sustainability of programme improvements: With the exception of Zimbabwe which is still in the early phase of rolling out an eHIS with UPI(39), all countries appear to have reached the middle stages of development for this element. This is due to progress made in the ability to track patients within a facility using the eHIS; challenges related to capturing and assigning of a UPI, as well as a lack of system integration, does however mean that tracking is largely still reliant on paper-based systems and personal information $(26-32,41)$. 


\section{Activity 3: A description of UPI implementation using sites in South Africa as a case study}

Results indicate that the recommended identifier, which is either the SA ID and/or SA passport/foreign passport number required for HPRS implementation and the generation of the UPI or HPRN(21) is often not captured at our selected clinics. Under half $(44 \%, \mathrm{~N}=289)$ of all files sampled had the SA ID number while exactly $50 \%(\mathrm{~N}=332)$ had either a SA ID or SA passport/foreign passport captured, refer to Figure 3 , with results varying across clinics and disease cohorts.

Within our study sample HIV files were more likely to have the recommend form of identifier captured, with $60 \%$ of all HIV files having either the SA ID or SA passport/foreign passport details on them. The TB cohort had the lowest proportion $(33 \%, \mathrm{~N}=37)$ of files with any of the required identifiers captured, followed by Diabetes and Hypertension files ( $46 \%$ and $47 \%$ respectively). Personal level identifiers (name and surname) were consistently captured across all facilities. None of the files in our sample were found to have a HPRN recorded.

Further analysis into HIV specific files (Figure 4) revealed process variances across clinics, Public site 1 and Public site 4 were more likely to capture either the SA ID number, SA passport number or foreign passport number ( $99 \%$ and $83 \%$ of all files respectively). In comparison just $19 \%$ of HIV files at Public site 2 and $41 \%$ of HIV files at Public site 3 had either a SA ID number, SA passport number or foreign passport number. $39 \%$ of all HIV files in our sample did not have any of these recommended identifiers captured.

\section{Discussion}

This landscape analysis sought to explore progress towards CBS, through the use of a UPI, in selected SADC countries. Our research revealed that while most countries remain in the early-middle stages of the move to a second-generation health information system, further development is hampered by challenges related to the UPI.

We found that patient monitoring and tracking, which is critical to improving the consistency of care in PLHIV and others, is reliant on the integration of all health systems; this integration is in turn dependent on the consistent assignment, recording and use of a UPI. Despite this, all countries which had rolled out an eHIS faced similar challenges with UPI implementation, this included multiple UPIs being assigned to one person, lost or forgotten system generated identifiers often linked to a smartcard as well as improper and inconsistent recording of the UPI by health personnel. Prior research has similarly identified challenges with UPI implementation amongst African countries as an obstacle to the evolution of paperbased health information systems (42) (35). Difficulties are reported to persist due to insufficient linkages between clinics, insufficient training of staff responsible for capturing unique identifiers, and staff shortages, resulting in some staff responsible for data management being stretched across multiple roles(43). Furthermore, HIV programme monitoring has been reported to be especially challenging due to both its scale and multiple data constraints, these include the lack of reliable information, and the 
continued use of paper registers which are often incomplete and lack unique identifiers (43); This is consistent with the findings from our South African case study which noted that the recommended patient identifier may often not be recorded on paper-files and therefore not transferred into the HPRS and Tier.net systems.

Paper-based records remain the preferred health information system despite the presence of an eHIS. Paper records were often implemented alongside the eHIS; a data officer was therefore required to capture information from paper files into the electronic system. Previous studies have similarly noted that paper-based record systems remain the main method for recording and tracking patient data in the region (16), and data entry into the electronic health record often falls upon the implementing partners (IPs). This was found to occur mainly from paper-based forms which have information collected by clinicians (37). In addition to the preference for the paper-based health system, we noted that the collection of personal identifiers into the eHIS also hampers CBS progress. Holmes et al. (19) similarly found that the lack of a unique identifier and poor levels of privacy and patient confidentiality acted as barriers to CBS progress and implementation.

Our country specific analysis suggests that limited implementation of the UPI as well as the persistence of the paper-based system, may perpetuate a reliance on aggregated monitoring systems. A previous study on surveillance mechanisms on the African continent also conclude that systems which measure, rather than aggregate and estimate disease burden over time still needed to be prioritized (10). Other studies also report data needing to be manually collected and aggregated for reporting on a monthly basis(43)(44). Another report noted that while data collection and monitoring of PLHIV is important for care outcomes, countries in the region lack comprehensive data and rely on aggregated datasets; disaggregation needs to be prioritised for the improvement of health outcomes(4). Our findings point towards the lack of UPI based integration between various stand-alone health information systems, such as the eHIS and the laboratory system, as also having an influence on the manner in which data is reported and analysed.

Finally, we found that all countries which formed part of this analysis had little to no UPI based integration amongst their many stand-alone health information systems. This may be due to overall poor UPI implementation or other technical factors. An earlier study identified the UPI as an important step in the integration of various sources of patient health information and the creation of longitudinal health records for patient monitoring and tracking(13). Systems integration has previously been noted as a challenge for countries in the region, resulting in incomplete viral-load reporting with some countries (4). Due to support within the HIV space through partners such as PEPFAR, UPI implementation and systems integration has been prioritised for PLHIV within the countries in our study, with a few exceptions such as the HPRS in South Africa which is said to run across disease areas. Beck et al. (13) also highlighted the need for integration across services as PLHIV who have non-communicable diseases (NCD's) will also need to be tracked, and such integration may contribute to the development of services for other chronic conditions in resource limited countries. The WCP in South Africa emerged as a leader in CBS implementation having achieved systems and service integration through the use of a UPI. Each patient 
is assigned a UPI and has a single health record with information incorporated from HIV, TB and antenatal services(8). Additional data sources include laboratory and dispensing data which is automatically incorporated into the system through integration with these databases(45).

There are several limitations to this study which indicate the need for further exploration of this subject area. One limitation is the lack of recent literature focussed specifically on reviewing progress of UPI implementation and challenges within the SADC region. We were extremely reliant on the PEPFAR COPS for specific countries during data collection. Other data sources included studies carried out between three to five years ago, which may contain information which is not currently relevant. While some incountry experts were consulted, a further limitation is the lack of external input. Future research should seek to understand the progress made in addressing the challenges of UPI implementation and identifying further barriers in the progression towards CBS by eliciting the viewpoints of health workers and other experts in the field.

\section{Conclusion}

This study has sought to provide a landscape analysis of advancement towards CBS utilising individual health records linked with a UPI within the SADC region. The UPI was found to play a critical role in systems integration and patient monitoring and the overall creation of stronger health information systems. Until a fully functional and reliable UPI is in place difficulties tracking patients across prevention and care cascades will continue. We have shown that progress towards CBS was lagging in all countries at the time of this study, consistently hampered by a preference for paper-based records and poor implementation of the UPI, underscoring a need for increased policy efforts and support to address this gap.

\section{Abbreviations}

ART: Antiretroviral

CBS: Case-based surveillance

CMIA: Client Management Information System

COP: Country Operational Plans

eHIS: Electronic Health Information System

EPMS: Electronic Patient Management System

EPTS: Electronic Patient Tracking System

HIS: Health information system 
HPRN: Health patient registration number

HPRS: Health Patient Registration System

ID: Identity

IPMS: Integrated procurement management system

MESH: Medical Subject Headings

NCDs: Non-communicable diseases

NHI: National Health Insurance

PHC: Primary healthcare

PIMS: Patient Information Management System

PLHIV: People living with HIV

SADC: South African Development Community

SA: South Africa

UPI: Unique patient identifier

WCP: Western Cape province

WHO: World Health Organisation

\section{Declarations}

\section{Acknowledgements}

We would like to acknowledge the in-country experts who took the time to share their knowledge and insights into the progress of UPI implementation for the countries specified in Activity 2. The authors are grateful to the staff and facility managers at our selected PHC clinics for the support provided during the data collection process for Activity 3 , and also recognise the efforts of the data collection staff involved in this process.

\section{Ethics approval and consent to participate}

Data collection for Activity 3 was approved by the Human Research Ethics Committee of the University of Witwatersrand (protocol no. M171082) and the Institutional Review Board of the Boston University Medical Centre (IRB no. H-37230). 


\section{Consent for publication}

Not applicable.

\section{Availability of data and materials}

All data generated for Activity 2 have been included as an attachment in this published article. The datasets generated and analysed for Activity 3 are available from the corresponding author upon reasonable request.

\section{Competing interests}

Not applicable.

\section{Funding}

This study was made possible by the generous support of the American people through the President's Emergency Plan for AIDS Relief (PEPFAR) through the United States Agency for International Development (USAID) under the terms of Cooperative Agreements AID 674-A-12-00029 and 72067419 CA00004 to HE2RO. The contents are the responsibility of the authors and do not necessarily reflect the views of PEPFAR, USAID or the US government. The funders of the study had no role in study design, data collection, data analysis, data interpretation, or writing of the report.

\section{Author contributions}

JM and LL conceived the study. KG prepared and analysed the data. KG, JM and LL contributed to the interpretation of results. KG wrote the first draft of the manuscript. This and all subsequent drafts were reviewed and revised by all authors. All authors read and approved the final manuscript.

\section{References}

1. World Health Organization. Everybody's business: Strengthening health systems to improve health outcomes-WHO's framework for action 2007 [Internet]. Geneva; 2007. Available from: https://www.who.int/healthsystems/strategy/everybodys_business.pdf

2. Ayanore MA, Amuna N, Aviisah M, Awolu A, Dramani D, Mogre V, et al. Towards Resilient Health Systems in Sub-Saharan Africa: A Systematic Review of the English Language Literature on Health Workforce, Surveillance, and Health Governance Issues for Health Systems Strengthening. Ann Glob Heal. 2019;85(1):1-15. 
3. Sherr K, Fernandes Q, Kanté AM, Bawah A, Condo J, Mutale W. Measuring health systems strength and its impact: experiences from the African Health Initiative. 2017;17(Suppl 3).

4. Avert.org. HIV and AIDS in East and Southern Africa regional overview [Internet]. 2019. Available from: https://www.avert.org/professionals/hiv-around-world/sub-saharan-africa/overview

5. Hansoti B, Mwinnyaa G, Hahn E, Rao A, Black J, Chen V, et al. Targeting the HIV Epidemic in South Africa: The Need for Testing and Linkage to Care in Emergency Departments. EClinicalMedicine [Internet]. 2019;15:14-22. Available from: https://doi.org/10.1016/j.eclinm.2019.08.007

6. Shamu S, Slabbert J, Guloba G, Blom D, Khupakonke S, Masihleho N, et al. Linkage to care of HIV positive clients in a community based HIV counselling and testing programme: A success story of nongovernmental organisations in a South African district. PLoS One. 2019;14(1):1-14.

7. Rosen S, Fox MP. Retention in HIV care between testing and treatment in sub-Saharan Africa: A systematic review. PLoS Med. 2011;8(7).

8. UNAIDS. Considerations and Guidance for Countries Adopting National Health Identifiers. 2014;1112. Available from: http://www.unaids.org/sites/default/files/media_asset/JC2640_nationalhealthidentifiers_en.pdf

9. Avert.org. HIV and AIDS in East and Southern Africa regional overview [Internet]. 2018. Available from: https://www.avert.org/professionals/hiv-around-world/sub-saharan-africa/overview

10. Nkumama I., O'Meara W., Osier FH. Changes in Malaria Epidemiology in Africa and New Challenges for Elimination. Trends Parasitol [Internet]. 2017;33(2):128-40. Available from: https://doi.org/10.1016/j.pt.2016.11.006\%0A

11. Havlir D, Lockman S, Ayles H, Larmarange J, Chamie G. What do the Universal Test and Treat trials tell us about the path to HIV epidemic control? J Int AIDS Soc. 2020;23:1-7.

12. Mapuroma R, Cohen C, Kuonza L, Musekiwa A, Tempia S, Tshangela A, et al. Healthcare seeking behaviour for common infectious syndromes among people in three administrative regions of Johannesburg, South Africa, 2015: a cross-sectional study. PanAfrican Med J [Internet]. 2019;8688:1-14. Available from: https://www.ncbi.nlm.nih.gov/pmc/articles/PMC6756806/pdf/PAMJ-33-159.pdf

13. Beck EJ, Shields JM, Tanna G, Henning G, De I, Andrews G, et al. Developing and implementing national health identifiers in resource limited countries: why, what, who, when and how? Glob Health Action [Internet]. 2018;11(1). Available from:

https://doi.org/10.1080/16549716.2018.1440782

14. World Health Organization. Consolidated guidelines on person-centred HIV patient monitoring and case surveillance [Internet]. 2017. Available from: https://www.who.int/hiv/pub/guidelines/personcentred-hiv-monitoring-guidelines/en/

15. Waruru A, Natukunda A, Nyagah LM, Kellogg TA, Zielinski-gutierrez E, Waruiru W, et al. No Title. JMIR Public Heal Surveill [Internet]. 2018;4(4). Available from: https://www.ncbi.nlm.nih.gov/pmc/articles/PMC6315226/?report=classic 
16. Hochgesang M, Zamudio-haas S, Moran L, Nhampossa L, Packel L, Leslie H, et al. Scaling-up health information systems to improve HIV treatment: An assessment of initial patient monitoring systems in Mozambique. Int J Med Inf. 2018;(97):322-30.

17. Katurura MC, Cilliers L, Africa S, Cilliers L, Cilliers L. Electronic health record system in the public health care sector of South Africa: A systematic literature review Research methodology. African J Prim Heal Care Fam Med. 2018;1-8.

18. Mills S, Lee JK, Rassekh BM, Zorko Kodelja M, Bae G, Kang M, et al. Unique health identifiers for universal health coverage. J Heal Popul Nutr. 2019;38(Suppl 1):1-8.

19. Holmes JR, Dinh T, Farach N, Manders E-J, Kariuki J, Rosen DH, et al. Status of HIV Case-Based Surveillance Implementation - 39 U . S . PEPFAR-Supported Countries. CDC: Morbidity and Mortality Weekly Report. 2019;68(47).

20. Harris P, Taylor R, Thielke R, Payne J, Gonzalez N, Conde J. Research electronic data capture (REDCap) - A metadata-driven methodology and workflow process for providing translational research informatics support. J Biomed Inf. 2009;42(2):377-81.

21. National Department of Health South Africa. National Digital Health Strategy for South Africa 2019 2024. 2019.

22. Davies M-A, Tsondai P, Tiffin N, Eley B, Rabie H, Euvrard J, et al. Where do HIV-infected adolescents go after transfer? - Tracking transition/transfer of HIV-infected adolescents using linkage of cohort data to a health information system platform. J Int AIDS Soc [Internet]. 2017;20:21668. Available from: https://www.ncbi.nlm.nih.gov/pubmed/28530037

23. Wall KM, Kilembe W, Inambao M, Chen YN, Mchoongo M, Kimaru L, et al. Implementation of an electronic fingerprint-linked data collection system: a feasibility and acceptability study among Zambian female sex workers. Global Health [Internet]. 2015 Jun;11:27. Available from: https://www.ncbi.nlm.nih.gov/pubmed/26115656

24. Harichund C, Haripersad K, Ramjee R. Participant verification: prevention of co-enrolment in clinical trials in South Africa. S Afr Med J [Internet]. 2013 May;103(7):491-3. Available from: https://www.ncbi.nlm.nih.gov/pubmed/23802218

25. Lambdin BH, Micek MA, Koepsell TD, Hughes JP, Sherr K, Pfeiffer J, et al. An assessment of the accuracy and availability of data in electronic patient tracking systems for patients receiving HIV treatment in central Mozambique. BMC Health Serv Res [Internet]. 2012 Feb;12:30. Available from: https://www.ncbi.nlm.nih.gov/pubmed/22296979

26. PEPFAR. Botswana Country Operational Plan (COP/ROP) 2019 Strategic Direction Summary. 2019;95. Available from: https://www.state.gov/wp-content/uploads/2019/09/Botswana_COP19Strategic-Directional-Summary_public.pdf

27. PEPFAR. Eswatini Country Operational Plan 2019 Strategic Direction Summary Table of Contents. 2019;2019(April).

28. PEPFAR. Lesotho Country Operational Plan (COP/ROP) 2019 Strategic Direction Summary. 2019;95. Available from: https://www.state.gov/wp-content/uploads/2019/09/Lesotho_COP19-Strategic- 
Directional-Summary_public.pdf

29. PEPFAR. Mozambique Country Operational Plan (COP/ROP) 2019 Strategic Direction Summary. 2019;95. Available from: https://www.state.gov/wp-content/uploads/2019/09/Mozambique_COP19Strategic-Directional-Summary_public.pdf

30. PEPFAR. Namibia Country Operational Plan (COP/ROP) 2019 Strategic Direction Summary. 2019;95. Available from: https://www.state.gov/wp-content/uploads/2019/09/Namibia_COP19-StrategicDirectional-Summary_public.pdf

31. PEPFAR. South Africa Country Operational Plan Strategic Direction Summary [Internet]. 2019. Available from: https://www.state.gov/wp-content/uploads/2019/09/South-Africa_COP19-StrategicDirectional-Summary_public.pdf

32. PEPFAR. PEPFAR Zambia Country Operational Plan (COP) 2019 Strategic Direction Summary April 12, 2019. 2019; Available from: https://www.state.gov/wpcontent/uploads/2019/09/Zambia_COP19-Strategic-Directional-Summary_public.pdf

33. Health Gap Global Access Project. COP20 COMMUNITY ZIMBABWE [Internet]. Vol. 22, Community Priorities. 2020. Available from: https://healthgap.org/wp-content/uploads/2020/02/CommunityCOP20-Zimbabwe.pdf

34. Measure Evaluation. Implementing Swaziland's client management information system. Vol. 8. 2017.

35. Mugomeri E, Olivier D, Heever WM Van Den. Health system challenges affecting the implementation of isoniazid preventive therapy in people living with HIV in Lesotho. HIV AIDS Rev. 2018;17(4).

36. Wright G, Mahony DO, Cilliers L. Electronic health information systems for public health care in South Africa: a review of current operational systems 10 th Health Informatics in Africa Conference ( HELINA 2017 ) Electronic health information systems for public health care in South Afri. J Heal Informatics Africa. 2017;4(1):51-7.

37. Gumede-Moyo S, Todd J, Bond V, Mee P, Filteau S. A qualitative inquiry into implementing an electronic health record system (SmartCare) for prevention of mother-to-child transmission data in Zambia: A retrospective study. BMJ Open. 2019;9(9):1-9.

38. Agolory S, De Klerk M, Baughman AL, Sawadogo S, Mutenda N, Pentikainen N, et al. Low case finding among men and poor viral load suppression among adolescents are impeding Namibia's ability to achieve UNAIDS 90-90-90 targets. Open Forum Infect Dis. 2018;5(9):1-8.

39. PEPFAR. PEPFAR Zimbabwe Country Operational Plan 2019 Strategic Direction Summary. 2019;80. Available from: http://www.pepfar.gov/documents/organization/250290.pdf

40. Munthali T, Musonda P, Mee P, Gumede S, Schaap A, Mwinga A, et al. Underutilisation of routinely collected data in the HIV programme in Zambia: A review of quantitatively analysed peer-reviewed articles. Heal Res Policy Syst. 2017;15(1):1-10.

41. PEPFAR. PEPFAR 2020 Country Operational Plan Guidance for all PEPFAR Countries. 2020.

42. Harklerode R, Schwarcz S, Hargreaves J, Boulle A, Todd J, Xueref S, et al. Feasibility of Establishing HIV Case-Based Surveillance to Measure Progress Along the Health Sector Cascade: Situational 
Assessments in Tanzania, South Africa, and. JMIR Public Heal Surveill [Internet]. 2017;3(3).

Available from: https://www.ncbi.nlm.nih.gov/pmc/articles/PMC5525003/

43. Etoori D, Wringe A, Kabudula CW, Renju J, Rice B, Gomez-olive FX, et al. Misreporting of Patient Outcomes in the South African National HIV Treatment Database: Consequences for Programme Planning , Monitoring, and Evaluation. 2020;8(April).

44. Moucheraud C, Schwitters A, Boudreaux C, Giles D, Kilmarx PH, Ntolo N, et al. Sustainability of health information systems: A three-country qualitative study in southern Africa. BMC Health Serv Res [Internet]. 2017;17(1):1-11. Available from: http://dx.doi.org/10.1186/s12913-016-1971-8

45. Boulle A, Heekes A, Tiffin N, Smith M, Mutemaringa T, Zinyakatira N, et al. Data Centre Profile: The Provincial Health Data Centre of the Western Cape Province, South Africa. Int J Popul Data Sci. 2019;4.

\section{Figures}




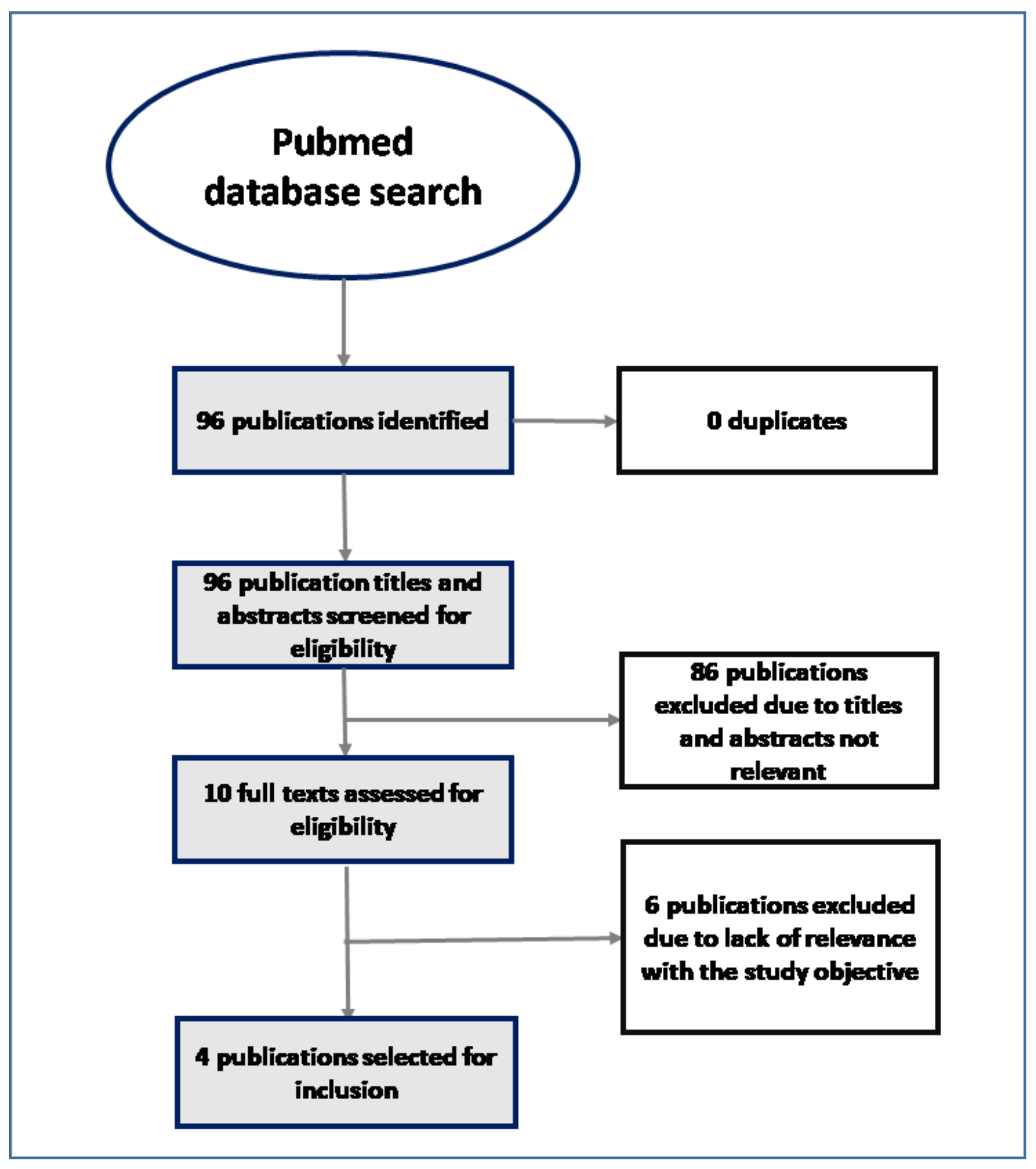

Figure 1

PRISMA flow diagram for the study selection process 


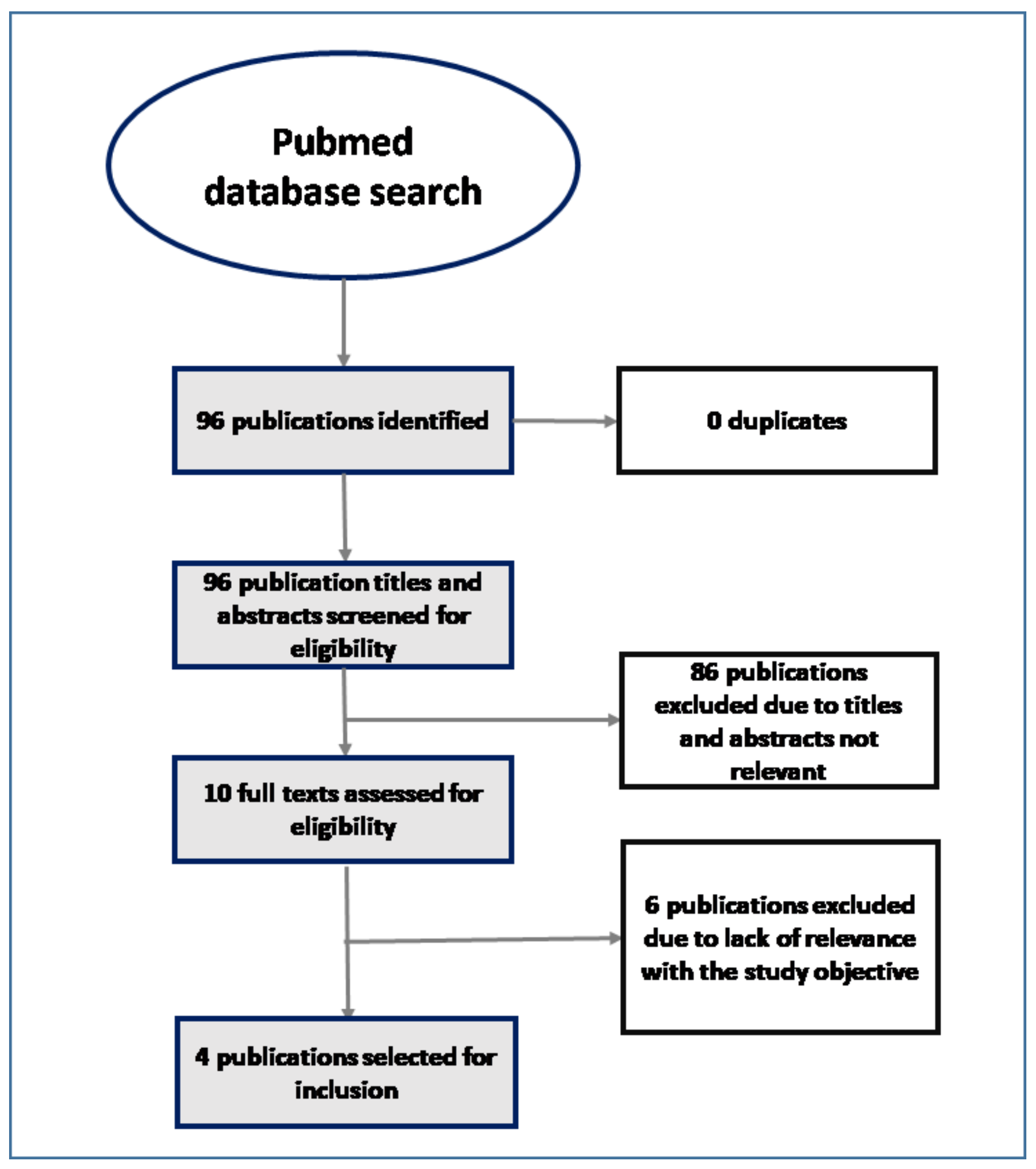

Figure 1

PRISMA flow diagram for the study selection process 


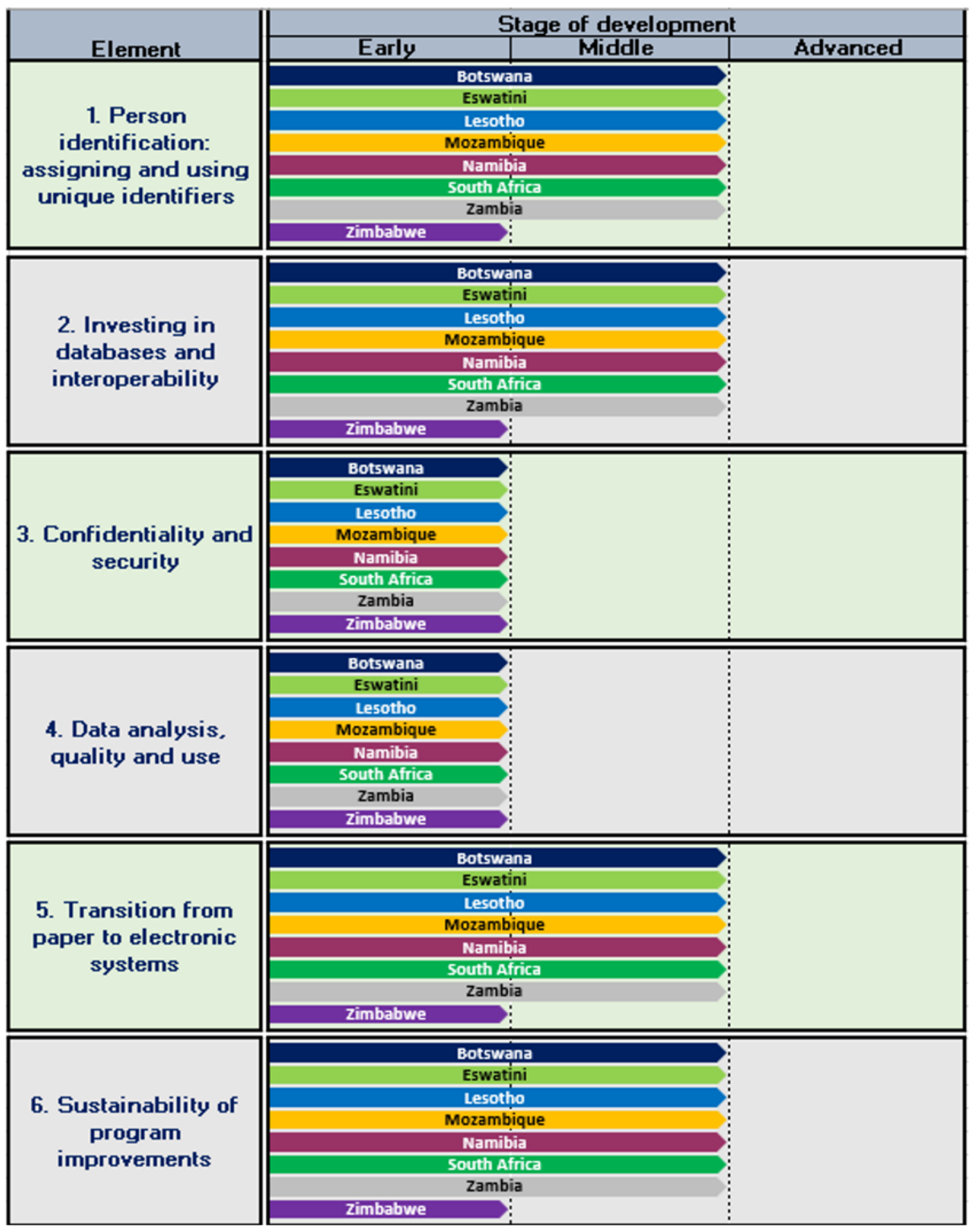

\section{Figure 2}

Comparison of results by the 7 key elements for the transition to CBS across the selected countries 


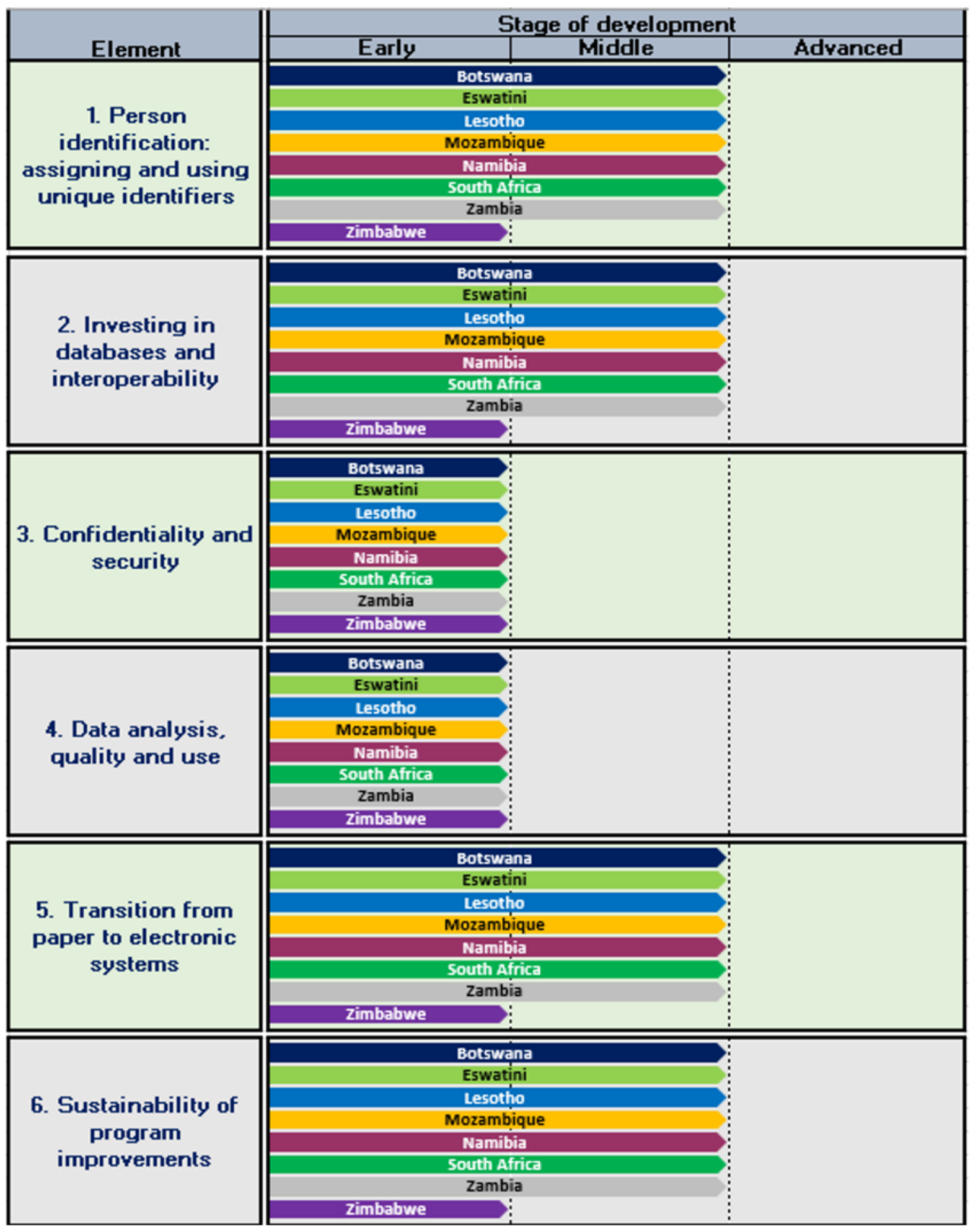

\section{Figure 2}

Comparison of results by the 7 key elements for the transition to CBS across the selected countries 


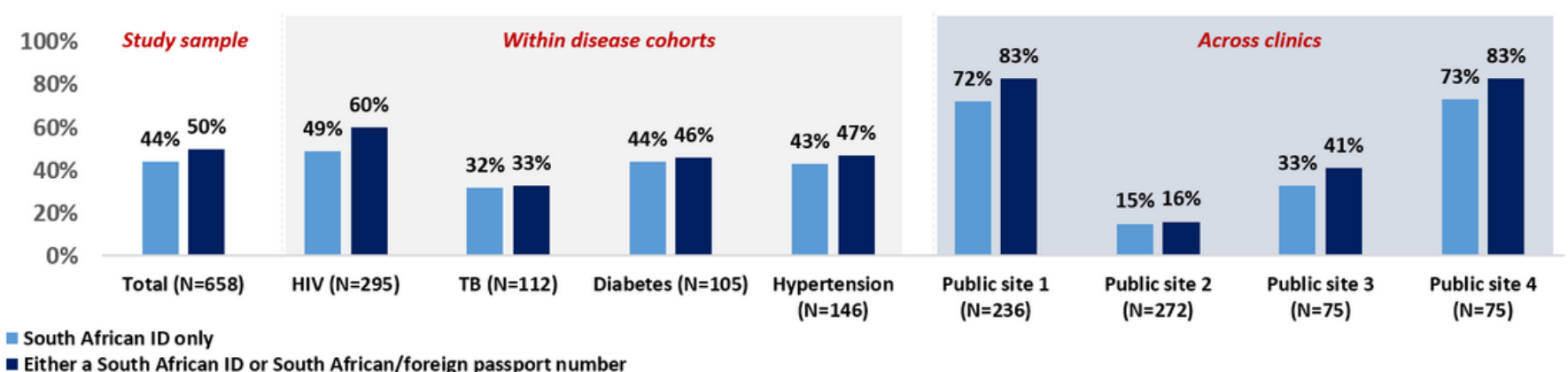

\section{Figure 3}

Proportion of files with a national ID and either a national ID or passport/foreign passport identifier captured for the study sample, and within each disease cohort

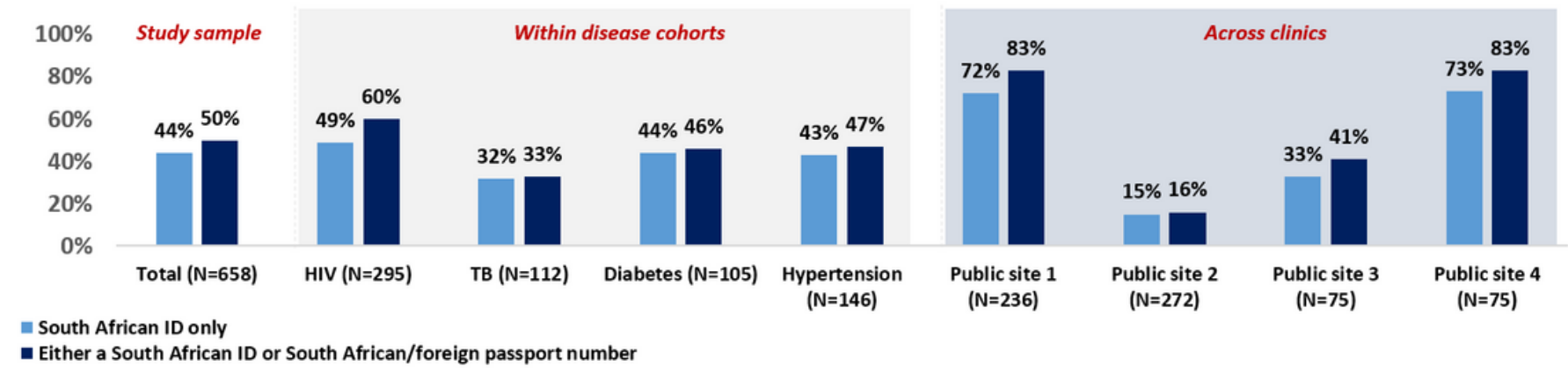

\section{Figure 3}

Proportion of files with a national ID and either a national ID or passport/foreign passport identifier captured for the study sample, and within each disease cohort 


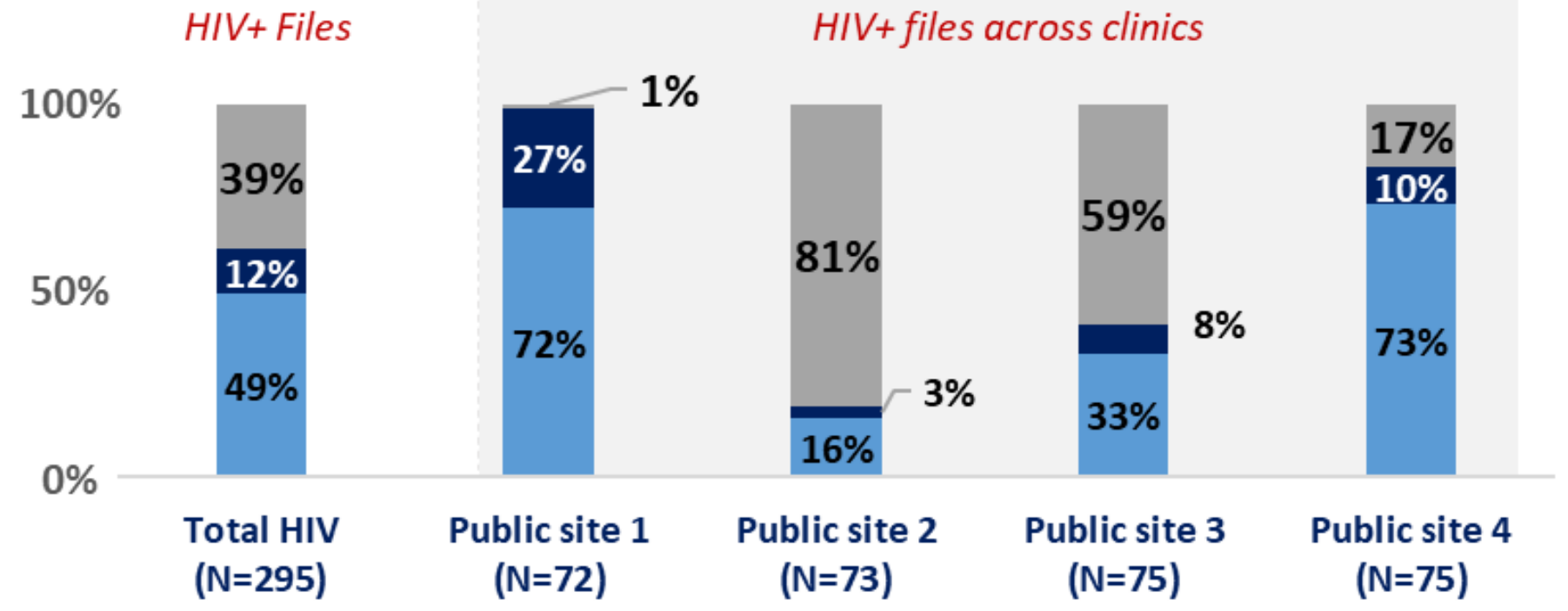

South African ID

South African/foreign passport number

Missing nationl ID or passport number

Figure 4

Results of an analysis into the types of identifiers captured on HIV patient files by study site 


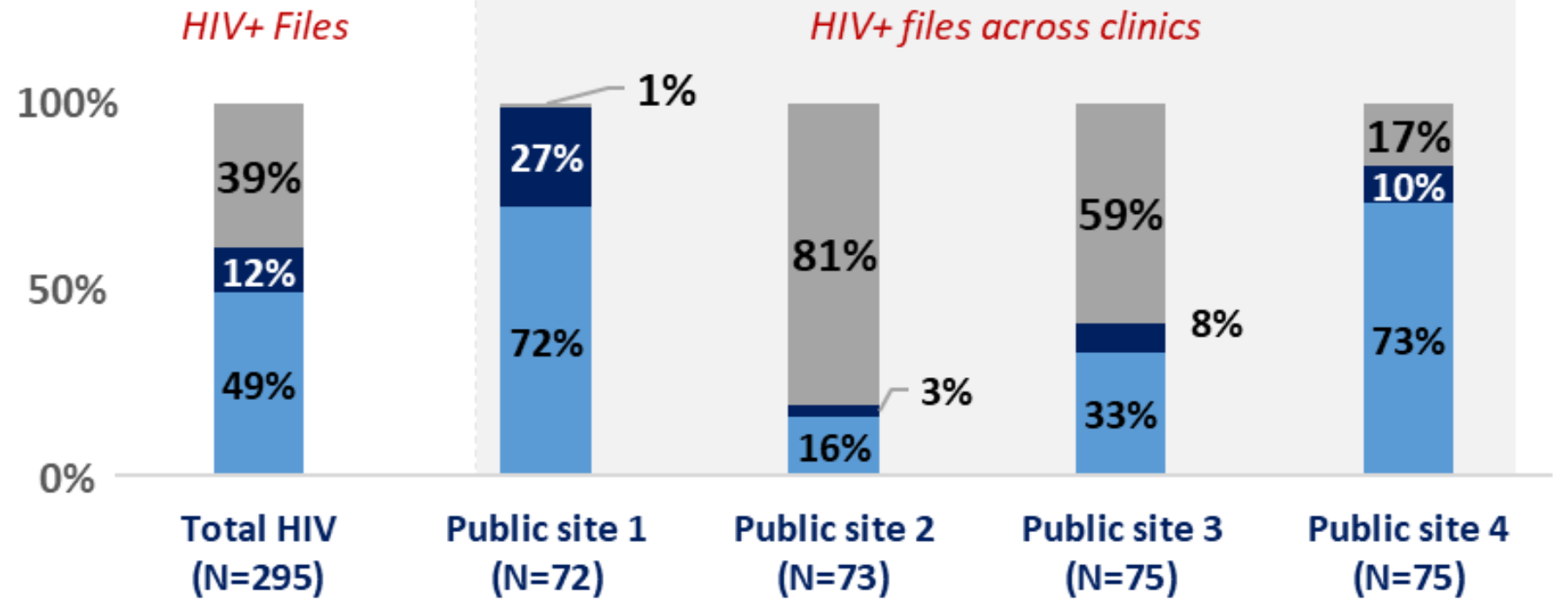

South African ID

South African/foreign passport number

Missing nationI ID or passport number

Figure 4

Results of an analysis into the types of identifiers captured on HIV patient files by study site

\section{Supplementary Files}

This is a list of supplementary files associated with this preprint. Click to download.

- Additionalfile1.xlsx

- Additionalfile1.xlsx 